\title{
Assistência Social na pandemia da covid-19: proteção para quem?
}

\section{Social Assistance in the covid-19 pandemic: protection for whom?}

\author{
Ivanete Boschetti ${ }^{a}$ \\ (D) https://orcid.org/ 0000-0002-3390-1556 \\ Elaine Rossetti Behring ${ }^{b}$ \\ (D) https://orcid.org/ 0000-0001-9523-160X
}

\begin{abstract}
Resumo: $\mathrm{O}$ artigo analisa as tendências da assistência social no Brasil nesse contexto de covid-19, que favorece programas de transferência monetária com valores muito aquém das necessidades sociais, que agudizam a condição de desigualdade social estrutural, aprofundada pelo ultraneoliberalismo e pelo neofascismo no Brasil. Esta combinação perversa, mórbida e tóxica nos levou ao lugar que ocupamos hoje na pandemia, mas é fato que tal projeto já encontra um país dilacerado pela crise econômica e social.
\end{abstract}

Palavras-chave: Assistência social. Precarização do trabalho. Ajuste fiscal. Contrarreforma.

\begin{abstract}
The article analyzes the trends in social assistance in Brazil in this context of covid-19, which favors cash transfer programs with values far below social needs, which aggravate the condition of structural social inequality, deepened by ultraneoliberalism and neo-fascism in Brazil. This perverse, morbid and toxic combination took us to the place that we occupy today in the pandemic, but it is a fact that such a project already finds a country torn apart by the economic and social crisis.
\end{abstract}

Keywords: Social Assistance. Precarious work. Fiscal adjustment. Counter-reform. 


\section{Apresentação}

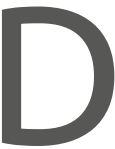

esde fevereiro de 2020, com a irrupção da pandemia causada pela covid-19, os números se agigantam no mundo - mais de 40 milhões de casos e 1,1 milhão de mortes ${ }^{1}$ - e no Brasil. As formas de seu enfrentamento pelos governos inundaram as mídias e revelaram desde posições sérias, contundentes e à altura da brutal crise sanitária, até posturas medíocres, negacionistas, ultraneoliberais, que nitidamente vilipendiaram o sofrimento das famílias acometidas pela doença. $O$ governo federal brasileiro, para nossa tristeza e indignação, nunca reconheceu a imensidão do problema, renegou seus efeitos sobre a classe trabalhadora mais exposta à contaminação, estimulou em parte da população posturas individualistas e contra as medidas sanitárias e o uso de medicamentos sem eficácia comprovada. Dois de seus ministros não resistiram, não aceitando rasgar seus diplomas de medicina frente às atitudes emanadas do Planalto. É evidente que as medidas adotadas favoreceram enormemente o capital - inclusive os dutos público-privados ilícitos, dos quais há inúmeros exemplos, sendo o mais ostensivo o Rio de Janeiro -, em detrimento do socorro às necessidades sociais da maioria da população.

Oito meses após as primeiras medidas divulgadas, e apesar da tendência lenta de redução dos casos e mortes, os dados são dramáticos: ultrapassamos 170 mil mortes, ${ }^{2}$ o que equivale aos habitantes de Rio das Ostras (RJ) ou Mogi Guaçu (SP), ${ }^{3}$ e 5,4 milhões de pessoas contagiadas pelo vírus, o que equivale a quase toda a população da cidade do Rio de

1 Disponível em: https://g1.globo.com/bemestar/coronavirus/noticia/2020/10/19/mundo-tem-mais-de-40-milhoes-de-casos-de-coronavirus-aponta-universidade-americana.ghtml: Acesso em: 19 out. 2020.

2 Até a data de 25 nov. 2020.

3 Conforme dados populacionais divulgados pelo IBGE em agosto de 2020. Disponível em: https:// www.ibge.gov.br/estatisticas/sociais/populacao/9103-estimativas-de-populacao.html?edicao $=28674 \& \mathrm{t}=$ resultados. Acesso em: 17 out. 2020 
Janeiro, ${ }^{4}$ e isto sem falar da imensa subnotificação, da ínfima testagem e das testagens inseguras, ${ }^{5}$ o que coloca o Brasil em terceiro lugar no número de casos, atrás apenas da Índia e dos EUA, e em segundo lugar no número de mortes, atrás apenas dos EUA. Essa redução em passos lentos, segundo Calil (2020), deve ser vista com cautela e ocorre no momento em que a pandemia revela novas tendências: 1) de interiorização; 2) de mudança no padrão etário dos infectados entre junho e agosto, com crescimento entre crianças e idosos e queda entre adultos; 3) de maior chance de infecção nos pretos e pardos e redução entre indígenas; e 4) de crescimento nas famílias entre as $20 \%$ mais pobres da população, com prevalência mais de duas vezes superior à observada entre os $20 \%$ mais ricos.

Os dados que emergem com a pandemia, contudo, revelam mais do que uma mera crise sanitária e desnudam a bárbara condição de desigualdade socioestrutural, aprofundada pelo ultraneoliberalismo, que se aliou, a partir de 2019, ao neofascismo no Brasil (Mattos, 2020). Essa combinação perversa, mórbida e tóxica nos levou ao lugar que ocupamos hoje na pandemia, mas é fato que tal projeto já encontra um país dilacerado pela crise econômica e social.

\section{Crise do capital e desigualdade social no Brasil}

Inegavelmente a pandemia da covid-19 implicou um curto-circuito no processo de produção e reprodução do capital, ao provocar a suspensão

4 Dados de 17 de outubro de 2020. Atualizados diariamente em: https://g1.globo.com/bemestar/ coronavirus/noticia/2020/10/17/casos-e-mortes-por-coronavirus-em-17-de-outubro-segundo-consorcio-de-veiculos-de-imprensa.ghtml.

5 Segundo o professor Domingos Alves, coordenador do Laboratório de Inteligência da Saúde (LIS) da Faculdade de Medicina da USP, o Brasil provavelmente já atingiu 18 milhões de infectados e mais de 200 mil mortes, se considerados os casos de "síndrome respiratória aguda grave (SRAG)" não especificados como sendo covid-19. Disponível em: https://www.bbc.com/ portuguese/brasil-54478219. Acesso em: 12 out. 2020. 
forçada da produção, distribuição e troca mundial de mercadorias, confirmando a atualidade da análise da lógica do capital e sua lei geral de acumulação desvendada por Marx em $O$ capital, em seus três livros. Quando as mercadorias não estendem seu olhar lânguido ao dinheiro e as metamorfoses entre D-M-D' são inviabilizadas, impõem-se as tendências de crise, com mercadorias e dinheiro em alqueive: crise de superprodução e de superacumulação. Se o capitalismo tende a situações cíclicas de desequilíbrios e curtos-circuitos em seu sociometabolismo, a pandemia, sem dúvida, é um catalisador potente de tais tendências. A crise do capital, sistêmica e estrutural, expressa, essencialmente, a contradição insolúvel do capitalismo, assentada na produção social e apropriação privada da riqueza, sustentada na exploração da força de trabalho e apropriação do trabalho excedente pelos capitalistas. A crise do capital é sempre uma crise de superprodução e superacumulação, elementos indissociáveis das relações de produção capitalista nos termos de Marx, como vimos. Mandel (1990) aponta que a manifestação das crises se expressa na superprodução, que revela a separação entre a produção de mercadorias e a existência de poder de compra disponível para adquiri-las ao preço desejado pelos proprietários, ou seja, aquele capaz de fornecer o lucro médio esperado e, para alguns, superlucros. Segundo Mandel (1990, p. 212):

É essa venda insuficiente, essa não estocagem, e essa redução da produção corrente que geram o movimento cumulativo da crise: redução do emprego, das rendas, dos investimentos, da produção, das encomendas; da espiral de redução do emprego, das rendas, dos investimentos, da produção etc.

Com tendência de queda nas taxas de lucro desde a crise do final dos anos 1960 e início dos anos 1970, agravada pelas seguidas crises dos anos 1980, 1990 e 2000, o mundo se defronta com a crescente destruição de postos de trabalho, o aumento do desemprego, a destruição das forças produtivas e imensos deslocamentos forçados em decorrência de guerras, violência e miséria. A onda longa com tendências de estagnação e seus movimentos internos de stop and go também expõe a escalada de 
confrontos geopolíticos e econômicos entre países e frações do imperialismo, a exemplo das tensões entre China e EUA, e ascensão da extrema direita e do neofascismo na arena internacional. A contraofensiva burguesa para assegurar os ganhos de produtividade e lucratividade ataca a classe trabalhadora, mediante contrarreformas que destroem direitos do trabalho e da Previdência Social, visando reduzir o valor da força de trabalho e valorizar o valor.

O Brasil, desde o golpe parlamentar de 2016 (com o apoio do empresariado, Judiciário e grande mídia), um momento de inflexão (Demier, 2017), avança a passos largos rumo à exacerbação do neoliberalismo, com aprofundamento das contrarreformas e privatizações. A eleição de 2018 quebrou o "ovo da serpente" e alçou ao poder um governo de extrema direita, ultraneoliberal e neofascista.

Há todo um debate acerca da caracterização do governo Bolsonaro e sua relação como fascismo, como regime ou governo. Vamos utilizar o termo neofascismo pelo argumento que segue. Para Ernest Mandel (1976), analisando o fascismo do entreguerras do século XX em diálogo com texto de Trotsky, é fundamental compreender a natureza e a função do fascismo para combatê-lo. Em que pese uma verborragia difusa sobre o tema, os regimes fascistas ao longo da história do século XX estiveram longe de colocar em questão as leis imanentes que regem o sistema capitalista, de forma que a análise materialista, histórica e dialética deve buscar trazer à tona o que tais regimes realmente fazem ou fizeram, e menos o que eles dizem ou disseram, ou seja, suas representações sobre si mesmos, em geral fantasiosas. A autonomia dos governos (e regimes) fascistas, enfim do poder político em relação às classes dominantes e às contradições econômicas, é muito relativa, sendo a maior expressão disso o militarismo, que longe está de ter sido ou ser hoje algo oposto ao capitalismo monopolista. Portanto, o fascismo denota a irracionalidade de conjunto do capitalismo em sua maturidade, que irrompe em condições políticas particulares, tendo uma origem de possível apreensão e inteligibilidade. 
Se os movimentos de massa pequeno-burgueses e fascistas mobilizam ontem e hoje o ódio e a agressividade, não é porque isso seja parte de uma espécie de natureza humana adormecida ou por razões meramente psicológicas. Essa necessidade do terror e da violência teve, na Itália e na Alemanha, profunda relação com o capitalismo monopolista e suas demandas de reprodução após a grande débâcle de 1929-32, bem como com o imperialismo, tendo em vista a retomada das taxas de lucro, inclusive pelo armamentismo. Tal dinâmica parece se recolocar após a profunda crise de 2008-9 ou seja, "o que é realmente essencial é a propriedade privada e a possibilidade de acumular capital e extrair mais-valia" (Mandel, 1976, p. 27). Nesse passo, o ascenso do fascismo foi (e, dizemos, é) expressão da grave crise do capitalismo maduro e decadente, uma crise de reprodução do capital. Nesse sentido, "a tomada do poder pelo fascismo é a alteração pela força e a violência, a favor dos grupos decisivos do capital monopolista, das condições de reprodução do capital" (Idem, p. 29). Se o fascismo não é a forma desejável e "normal" da dominação burguesa, não há pudores em lançar mão do mesmo em condições determinadas - de crise -, mobilizando a fração enfurecida pequeno-burguesa para esmagar as organizações operário-populares, na forma de falanges e esquadrões paramilitares inclusive. O fascismo busca o "esmagamento da classe operária, a destruição das suas organizações e a supressão das liberdades políticas no momento em que os capitalistas se mostram incapazes de governar e de dominar com a ajuda da mecânica democrática”, colocando a pequena burguesia “à disposição de seus piores inimigos" (Trotsky, 1976, p. 117).

A partir dessas considerações, podemos sintetizar que há nítidos elementos de fascismo naquilo que o bolsonarismo está fazendo no seu conjunto e desencadeando na sociedade brasileira num contexto de crise estrutural do capitalismo (Mandel, 1972/1982 e Mészáros, 2002), ainda que não tenha se instaurado um regime fascista - uma ditadura aberta. No entanto, temos uma espécie de simulacro frente aos fascistas do passado, em que o "nacionalismo" vem associado à entrega do patrimônio público ao usufruto do imperialismo, o "combate à corrupção" significa 
aparelhar as instituições para interesses escusos, as eleições gerais são contaminadas pela prisão do adversário e pelas fake news em associação com a Cambridge Analytica. ${ }^{6}$ Pelo exposto, vamos utilizar o termo neofascismo para caracterizar o governo, não o regime. ${ }^{7}$

No âmbito da economia, o presidente se cercou do que há de mais liberal, com Paulo Guedes à frente, dando sequência à programática ultraneoliberal do golpe de 2016 e sendo ovacionado pela maioria do empresariado, que aplaude e estimula as privatizações, a destruição da natureza com queimadas criminosas, a destruição dos direitos sociais, uma "reforma" fiscal que pretende desvincular todos os gastos sociais do orçamento e intensificar a contrarreforma trabalhista, para tornar o trabalho ainda mais subsumido ao capital. A Lei da Liberdade Econômica (Lei no 13.874/2019) e a Contrarreforma da Previdência (EC no 103/2019) se somam aos instrumentos já em vigor do ajuste fiscal permanente (Behring, 2019) - Lei da Terceirização (Lei no 13429/2017), Contrarreforma Trabalhista (Lei no 13467/2017), o teto de gastos (Emenda Constitucional n० 95) - para estabelecer as garantias necessárias ao livre-mercado e à redução dos direitos, como requisitos da acumulação. Na contundente análise de Fiúza (2020), ${ }^{8}$ vivemos sob o "ultraneoliberalismo fascista", que aprofunda o neoliberalismo, sem romper com seus preceitos:

O neoliberalismo passou e segue passando por transformações a partir de novos arranjos, da apropriação de pautas progressistas em determinado momento do ciclo histórico, culminando em sua face ultraneoliberal no momento presente, que não rompem nunca, entretanto, com seus principais objetivos e fundamentos.

6 Cambridge Analytica é a empresa que coletou ilegalmente dados de 87 milhões de usuários do Facebook e virou alvo de investigações em diferentes países. 0 uso desses dados em campanhas da extrema direita está retratado no documentário intitulado Privacidade Hackeada.

7 Essas reflexões acima sobre o neofascismo estão em Behring, 2020, Capítulo 8.

8 Ver a série de três textos de Juliana Fiúza, no Esquerda Online. Disponível em: https://esquerdaonline.com.br/colunistas/juliana-fiuza-cislaghi/. Acesso em 15 out. 2020. 
O ultraneoliberalismo é reforçado também por um reacionarismo violento - neofascista — que se evidencia em discursos e ações de criminalização das lutas sociais e do pensamento de esquerda, que fortalece o negacionismo e persegue a autonomia da pesquisa, da formação e da produção de conhecimento, com ataques virulentos contra as universidades públicas. $\mathrm{O}$ conservadorismo moral negligencia os direitos humanos e as conquistas civilizatórias no campo da cidadania constitucional. A investida contra os direitos conquistados pelas mulheres na forma de crítica à "ideologia de gênero" se adensa com uma profunda LGTBfobia, manifestações racistas e destruição da vida dos povos originários. A militarização do governo "democraticamente" eleito conduz cada vez mais as ações governamentais, com 6.157 militares da ativa e da reserva em cargos civis, segundo o Tribunal de Contas da União (TCU), mais que dobrando essa presença em relação ao governo Michel Temer, que chegou a ter 2.765 militares em cargos federais. ${ }^{9}$

Os draconianos ajustes fiscais (Boschetti e Teixeira, 2019; Behring, 2019) impulsionados nos últimos anos não provocaram a recuperação econômica anunciada: o Produto Interno Bruto (PIB) de 2018 cresceu apenas 1,3\% e o de 2019 caiu para 1,1\%, tendo sido apelidado de "pibinho", subscrevendo a ausência de decolagem econômica. Antes mesmo da pandemia, portanto, a economia patinava insistentemente, o que sustentou a encarniçada destruição da previdência pública, como estratégia de transferência antes nunca vista de fundo público ${ }^{10}$ para o capital,

9 Cf. noticiado pelo jornal O Globo. Disponível em: https://g1.globo.com/politica/noticia/2020/07/17/governo-bolsonaro-tem-6157-militares-em-cargos-civis-diz-tcu.ghtml. Acesso em: 16 out. 2020.

10 Segundo Behring (2020), o fundo público é a base material da atuação do Estado numa sociedade monetizada e reúne o conjunto dos recursos que o Estado capitalista mobiliza para o desenvolvimento de suas funções - de garantia das condições gerais de produção e reprodução, de coerção e de legitimação (Mandel, 1972/1982). O fundo público se forma por meio da capacidade extrativa do Estado, diga-se, da tributação, ainda que não exclusivamente (endividamento, emissão de moeda, entre outros expedientes). Essa capacidade extrativa incide sobre as personas do capital - juros, lucros, renda da terra - e também sobre os salários, ou seja, sobre a mais-valia socialmente produzida e sobre o fundo de reprodução da força de 
especialmente o financeiro. É um verdadeiro processo de expropriação do fundo público drenado para salvar o capital em crise (Boschetti, 2016 e 2018), que agrava a estrutural desigualdade social, evidenciada por mais de 12,6 milhões de desempregados em 2019, que, somados aos precarizados e "desalentados", chegou a 32 milhões, sendo que um em cada quatro trabalhadores(as) estava desempregado havia mais de dois anos, conforme PNAD Contínua divulgada em setembro de 2019. A mísera queda na taxa de desemprego de $11,8 \%$ para $11,0 \%$, festejada pelo governo, escondeu os efeitos da contrarreforma trabalhista e da terceirização de 2017, que provocaram ampliação de trabalhos precarizados e sem direitos, já que a informalização atingiu $41,1 \%$ da população ocupada, o maior nível desde 2016.

Portanto, quando a pandemia chega ao Brasil, encontra um país com 12,6 milhões de desempregados(as). Esse dramático número encobre a condição de desigualdade de gênero e raça que atinge as mulheres e negros(as). Entre os(as) desempregados(as), 64,8\% são pretos e pardos, conforme designação da PNAD/IBGE, enquanto os(as) que são brancos(as) correspondem a $34,2 \%$. As mulheres são a maior parte $(64,7 \%)$ da força de trabalho e também são maioria entre a população sem emprego $53,8 \%$. A taxa de desemprego entre as mulheres foi de $13,1 \%$ contra $9,2 \%$ entre os homens. O nível da ocupação dos homens foi de $65 \%$, enquanto o das mulheres foi de 46,2\% (IBGE, 2019). Assim, as mulheres negras compõem a principal força de trabalho desempregada, precarizada e com baixos salários, o que revela a natureza estruturalmente racista e patriarcal do capitalismo brasileiro (Almeida, 2018).

trabalho - o trabalho necessário. Assim, o fundo público é um compósito de trabalho excedente e trabalho necessário. No ambiente do neoliberalismo e da crise estrutural do capital, o fundo público, além de incidir cada vez mais sobre a renda do trabalho, vem sendo disputado como um pressuposto muito requisitado para a reprodução ampliada do capital, num processo com fortes consequências políticas, a exemplo do ascenso da extrema direita ao poder no Brasil e em outros países do mundo, tendo em vista sua alocação para os interesses do capital, destacadamente na administração da crise. 
A condição do trabalho no Brasil determina o acesso a duas das principais políticas sociais que compõem a seguridade social e são as únicas que garantem acesso a benefícios monetários mensais: a Previdência Social, vinculada ao trabalho formalizado ou a uma contribuição direta feita mensalmente pelos(as) trabalhadores; e a assistência social, canalizada para pessoas pobres sem condições de trabalhar por idade ou incapacidade por meio do Benefício de Prestação Continuada (BPC) que atingia 4,7 milhões de idosos e pessoas com deficiência em 2019, ou para famílias miseráveis sem trabalho, por meio do Bolsa Família, que alcançava 14,2 milhões de famílias nesse ano (aproximadamente um em cada cinco brasileiros[as]).

Isso significa que a reprodução da força de trabalho sem emprego só está assegurada pelos direitos trabalhistas como seguro-desemprego ou pelos direitos previdenciários, como aposentadorias, pensões e auxílios (doença, reclusão) para aqueles(as) que contribuíram; ou pela assistência social para quem não cumpre as regras contributivas dos seguros sociais. Isso significa dizer que, em 2019, as 38,7 milhões de pessoas ocupadas (que não são consideradas desempregadas pelo IBGE) que não contribuíram para a Previdência Social dificilmente terão possibilidade de acessar os direitos trabalhistas e previdenciários. Se forem consideradas pobres, miseráveis ou incapazes pelos critérios assistenciais, poderão solicitar um de seus benefícios monetários. Se não forem "incluídos" pelos severos critérios assistenciais, serão obrigados a se disponibilizar "livres como pássaros" (Marx, [1867] 2013) para "negociar" no mercado as formas mais bárbaras de exploração, sem nenhum tipo de proteção social mediada pelo Estado. Não são “invisíveis", como se ouviu durante a pandemia. São uma imensa parcela da classe trabalhadora que constitui o que Marx ([1867] 2013) identificou como a superpopulação flutuante e estagnada, necessária para a reprodução do capital, seja para pressionar a redução do valor da força de trabalho, seja para manter o mercado consumidor. Será para sua proteção que a assistência social se agigantou durante a pandemia, em forma do "auxílio emergencial"? 


\section{Assistência social na pandemia: proteção ao trabalho ou ao capital?}

A pandemia, inquestionavelmente, revelou ao país e ao mundo o que o país insistia em ocultar: o desmonte da seguridade social e dos direitos trabalhistas ${ }^{11}$ pelos sucessivos ajustes fiscais deixaram o Brasil imensamente vulnerável diante da devastação do acelerado processo de contágio. Por um lado, o Sistema Único de Saúde (SUS), legalmente universal e descentralizado, mas que já agonizava com falta de recursos - o orçamento federal para a saúde já vinha desde 2015 congelado no patamar de 1,7\% do PIB, o que não foi revertido com a leve recomposição feita pelo "orçamento de guerra" na saúde -, entrou em colapso diante das novas, desconhecidas e imensuráveis demandas da covid-19. De outro lado, a intensa precarização das relações e condições de trabalho faz emergir um universo de trabalhadores e trabalhadoras (mais de 100 milhões de pessoas ou quase 50\% da população) que se viram, da noite para o dia, sem trabalho, sem nenhum tipo de remuneração, sem benefícios assistenciais e sem condições de seguir buscando nas ruas algum tipo de atividade precarizada (as atividades informais) que lhes assegurasse uma forma de rendimento e de sobrevivência.

Ao retardar e resistir a exercer sua reponsabilidade pública e assegurar os recursos públicos e as medidas econômicas, sociais e sanitárias necessárias ao enfrentamento da pandemia e dos casos que se multiplicaram violentamente, o governo federal negacionista, ultraneoliberal e neofascista favoreceu também a multiplicação e a agudização das desigualdades estruturais. Os mais atingidos pela pandemia foram a parcela mais pobre da classe trabalhadora, moradora das favelas e periferias sem condições adequadas de saneamento e meios de prevenção, com dificuldades de acesso ao SUS saturado, sendo a maioria de pessoas

11 Sobre os impactos dos ajustes fiscais, sobretudo o teto de gastos na seguridade social, consultar Boschetti e Teixeira (2019) e Salvador (2020). Para os impactos na destruição dos direitos trabalhistas, consultar Cavallazzi e Silva (2020). 
negras. Interessante estudo do Instituto Polis na cidade que concentra o maior número de casos e óbitos revela as dimensões de gênero e raça da pandemia: enquanto entre a população branca o número de óbitos em São Paulo (até 31/7) foi de 115 para cada 100 mil habitantes, entre a população negra chegou a 175 para cada 100 mil. Entre homens negros chegou a 250 óbitos para cada 100 mil habitantes, enquanto entre homens brancos foi de 157 para cada 100 mil. Entre as mulheres negras, o número de óbitos foi de 140 mortes para cada 100 mil habitantes, enquanto entre as mulheres brancas foi de 85 óbitos para cada $100 \mathrm{mil}$ habitantes. ${ }^{12}$

As tímidas, reticentes e retardatárias medidas federais seguiram a mesma política ultraneoliberal já em curso: parcos recursos para a saúde e para o auxílio emergencial e trilhões para bancos e empresários, conforme aprovado no chamado “orçamento de guerra” (EC no 106/2020), que instituiu o "regime extraordinário fiscal, financeiro e de contratações para enfrentamento de calamidade pública nacional decorrente da pandemia”. Na análise da Auditoria Cidadã da Dívida (ACD), o seu real objetivo é "legalizar a indecente remuneração da sobra de caixa dos bancos que desviou, de forma ilegal, cerca de $\mathrm{R} \$ 1$ trilhão de recursos públicos em 10 anos (2009 a 2018), segundo dados do balanço do próprio Banco Central, além de jogar os gastos com a calamidade do coronavírus nas contas das áreas sociais". Em nota técnica divulgada ainda em abril de 2020, durante a tramitação da PEC do Orçamento de Guerra, a Auditoria Cidadã da Dívida denunciava o real significado e intencionalidade do ministro Guedes: favorece o setor financeiro, que já havia recebido aporte de $R \$ 1,2$ trilhão em lastro para a oferta de crédito; autoriza a retirar os recursos de áreas sociais durante a pandemia, mas não atinge centenas de bilhões que só podem ser destinados ao pagamento dos juros e amortizações da dívida pública; visa "legalizar" a emissão de títulos da dívida pública para pagar as despesas correntes com juros dessa dívida, o que burla o art. 167, III, da própria Constituição; visa “legalizar” mecanismo

12 Disponível em: https://polis.org.br/estudos/raca-e-covid-no-msp/. Acesso em: 18 out. 2020. 
fraudulento que tem aumentado ilegalmente o estoque da dívida, usando recursos de capital para pagar as privilegiadas despesas correntes com juros; promove salvamento de empresas e bancos, transferindo para os cofres públicos o ônus de papéis podres em poder do mercado (tal como ocorreu nos EUA e na Europa na crise de 2008, afetando gravemente os cofres públicos), com aporte de $25 \%$ do Tesouro Nacional, sem exigir contrapartida alguma das empresas e bancos beneficiados. ${ }^{13}$

É importante não esquecer que, enquanto o "orçamento de guerra" propunha esses verdadeiros presentes ao capital, para a classe trabalhadora sem rendimento o governo federal propôs o auxílio emergencial no valor de míseros $R \$ 200,00$ (que foram recompostos pelo Congresso para $R \$ 600,00)$, a suspensão dos contratos de trabalho com redução salarial e a facilidade para empregadores interromperem os contratos de trabalho. Dos 108 milhões de trabalhadores(as) que solicitaram o auxílio emergencial, somente 68 milhões receberam, chegando a 44\% dos domicílios brasileiros. Em contraposição, somente 4,2 milhões solicitaram seguro-desemprego até agosto de 2020. Esses números mostram a redução cada vez maior dos direitos trabalhistas e a ampliação do benefício assistencial na reprodução da força de trabalho.

Numa sociedade monetizada, marcada pela lógica do valor - o que envolve produção e reprodução - , quem não tem renda alguma se aproxima da morte e da brutalidade provocada cotidianamente pelo pauperismo. ${ }^{14}$ Este debate envolve como prover as necessidades mais elementares para as maiorias que hoje - no Brasil e no mundo - não encontram emprego ou, quando o encontram, se deparam com uma imensa precarização, baixos salários, superexploração. Os programas de "transferência de renda" que se espraiam nos países capitalistas desde

13 Disponível em: https://auditoriacidada.org.br/conteudo/note-tecnica-pec-do-orcamento-de-guerra/ Acesso em: 18 out. 2020.

14 Os dois parágrafos seguintes foram publicados pelas autoras no texto “"Transferência de renda', teto de gastos e oportunismo: para uma crítica de esquerda”. Disponível em: https:// esquerdaonline.com.br/2020/08/18/transferencia-de-renda-teto-de-gastos-e-oportunismo-para-uma-critica-de-esquerda/: Acesso em: 18 out. 2020. 
a crise da década de 70 longe estão de serem políticas de esquerda, mas têm sido sucessivamente utilizados por partidos de direita e da social-democracia, com diferentes tonalidades e abrangência, diante da incapacidade de o capitalismo assegurar pleno emprego. Em sua origem, foram defendidos por neoliberais como Milton Friedman, sempre com valores baixíssimos para não desestimular o trabalho, mesmo que não haja trabalho para todos e todas. O Bolsa Família, que resultou da unificação de vários auxílios assistenciais pontuais e focalizados, foi implantado no Brasil em 2003, no início do governo Lula, na esteira de expansão desses programas em toda a América Latina. Essa era nossa crítica ao Programa Bolsa Família: seu não reconhecimento como direito social, o que possibilita seu uso de forma clientelista, seus valores extremamente rebaixados, sua ínfima parte na alocação do fundo público, mas com grande saldo político.

Os programas assistenciais de "transferência de renda" são estratégias político-econômicas importantes para garantir minimamente a sobrevida de trabalhadores(as), de modo a garantir sua disponibilidade para a exploração; para assegurar um fluxo básico de consumo, evitando um curto-circuito na rotação do capital, e para controlar socialmente o pauperismo e os comportamentos das "classes perigosas". No entanto, para quem está desprovido de todas as condições de reprodução social no capitalismo, programas que transferem recursos públicos sob a denominação de "transferência de renda", "renda básica" ou "renda mínima" são uma questão de vida ou de morte, ainda mais em países como o Brasil, marcado pela informalidade, baixos e instáveis salários e precarização agressiva. A bárbara condição de mais de 100 milhões de homens e mulheres se tornou explosiva na pandemia. Se a "transferência de renda" é funcional à reprodução do capitalismo, não se pode negar que é igualmente necessária para reprodução da classe trabalhadora. Por isso, a esquerda deve fazer a defesa tática da "transferência de renda", não nos termos e parâmetros panópticos e draconianos das propostas neoliberais - mesmo de um neoliberalismo de cooptação, conforme a análise de Cislaghi (2020). 
Esse é o desenho que deverá ser reeditado pelo "museu de grandes novidades" do bolsonarismo com a proposta do programa Renda Brasil ou Renda Cidadã, que inclusive patina, já que as únicas formas que esse governo consegue pensar para financiar uma ampliação da abrangência e dos valores do atual Bolsa Família, tendo em vista garantir alguma legitimidade entre os pauperizados, são fortemente regressivas e destrutivas de direitos. Querem manter o teto de gastos a qualquer custo, e para isso cogitam se apropriar de recursos do Fundeb, do seguro-desemprego, do abono salarial e de outras rubricas. Tudo isso para financiar uma proposta meramente eleitoreira e que fez brilhar os olhos presidenciais com o sucesso da "Bolsa-Capitão" - o auxílio emergencial - nas pesquisas de opinião para 2022. A defesa tática da transferência de renda deve, portanto, incorporar a ideia de uma renda de, no mínimo, $R \$ 600,00$, financiada pelo imposto sobre grandes fortunas, por uma gestão soberana da dívida pública auditando e quiçá fechando a gambiarra de recursos para o pagamento de juros, encargos e amortizações da mesma, entre outras possibilidades.

Do ponto de vista do orçamento público, podemos vislumbrar um aumento significativo de recursos da Assistência Social, que saltou de $\mathrm{R} \$$ 95,2 bilhões, em 2019, para $\mathrm{R} \$ 298,7$ bilhões (referente aos valores pagos até agosto de 2020 e que ainda crescerá até o final de 2020), devido à "transferência de renda", com corte de recursos de outras políticas e rubricas centrais, como educação $0^{15}$ e saúde. Fica evidente que os recursos do auxílio emergencial drenam recursos do Fundo Nacional de Assistência Social, especialmente dos investimentos nos serviços socioassistenciais, que tiveram agressiva redução de 38,6\% entre 2012 e 2018, com a participação no FNAS caindo de 5,6\%, em 2012, para 2,8\%, em 2019, o que se agravará em 2020. Também vem ocorrendo perda gigantesca

15 Vejamos a função Educação, a partir de breve incursão no Siga Brasil. Temos um orçamento em queda entre $\mathrm{R} \$ 109,3$ bilhões em 2015, com leve recomposição para $\mathrm{R} \$ 112,3$ bilhões em 2017 , seguida de uma aguda queda para $\mathrm{R} \$ 96,8$ bilhões em 2019. Até agosto de 2020, a execução do orçamento da educação estava em $R \$ 58,3$ bilhões, o que sinaliza uma trajetória de continuidade para baixo, inclusive com um contingenciamento de $\mathrm{R} \$ 4$ bilhões. 
de recursos dos programas, projetos e ações da gestão do Suas, com redução de 15,5\% entre 2012 e 2018 e diminuição de sua participação no FNAS de 0,8\%, em 2013, para 0,4\%, em 2018. Os dados disponíveis no Siga Brasil revelam que os recursos para o Suas (exceto BPC e RMV) em 2019 haviam sofrido redução de $2 \%$ em relação a 2018. E a proposta de Lei Orçamentária para 2020 previa somente $\mathrm{R} \$ 1,344$ bilhão para o Suas (exceto BPC), o que significa uma queda de $31 \%$ em relação ao valor gasto em 2019, ou seja, trata-se de uma política de cobertor curto, que tira dos serviços e direitos para a "transferência de renda", em proporções muito maiores do que já vinha ocorrendo.

$\mathrm{O}$ que se vislumbra é um processo acelerado e ampliado de assistencialização/assistencialismo voltado para o pauperismo absoluto, o que difere imensamente do direito à assistência social. Este último pode e deve compor uma política de seguridade social, fundada em trabalho estável com direitos, previdência e saúde públicas e universais. Como direito social, programas de "renda básica universal" podem complementar ou substituir temporariamente a perda de direitos do trabalho, mas jamais terão a capacidade de reduzir desigualdades no acesso à riqueza socialmente produzida. Sua expansão expõe, na verdade, a incapacidade do capitalismo de superar suas crises. A substituição de empregos estáveis e com direitos por programas assistenciais de "transferência de renda" clientelistas revela a mais brutal forma de subsunção do trabalho ao capital: além de manter a classe trabalhadora sem trabalho a baixo custo, nos limites da sobrevida, também age para rebaixar o valor dos salários, transfere para o Estado a quase totalidade dos custos da reprodução da força de trabalho, já que desonera o capital, e cria um ciclo de reprodução de desigualdades ainda mais perene, pois interdita o acesso de homens e mulheres a possibilidades de trabalho com direitos. Nesse sentido é que indagamos a quem essa concepção assistencialista - e que vai na contramão das formulações constitucionais - quer proteger. A nosso ver, ela objetiva garantir proteção ao capital, e não à classe trabalhadora. Quer evitar que as "classes perigosas" se rebelem, no mesmo passo em que realizam a gestão de um curto-circuito econômico no processo de reprodução. 


\section{Referências}

ALMEIDA, Silvio Luiz de. O que é racismo estrutural? Belo Horizonte: Letramento, 2018.

BEHRING, Elaine Rossetti. Ajuste fiscal permanente e contrarreformas no Brasil de redemocratização. In: SALVADOR, E; BEHRING, E.; LIMA, R. L. (orgs.). Crise do capital e fundo público: implicações para o trabalho, os direitos e a política social. São Paulo: Cortez, 2019.

BEHRING, Elaine Rossetti. Fundo público, valor e política social. 2020. No prelo.

BEHRING, Elaine; BOSCHETTI, Ivanete. "Transferência de renda”, teto de gastos e oportunismo: para uma crítica de esquerda. Disponível em: https:/esquerdaonline.com. br/2020/08/18/transferencia-de-renda-teto-de-gastos-e-oportunismo-para-uma-criticade-esquerda/. Acesso em: 18 out. 2020.

BOSCHETTI, Ivanete. Assistência social e trabalho no capitalismo. São Paulo: Cortez, 2016.

BOSCHETTI, Ivanete. Expropriação de direitos e reprodução da força de trabalho. In: BOSCHETTI, I. (org.). Expropriação e direitos no capitalismo. São Paulo: Cortez, 2018.

BOSCHETTI, Ivanete; TEIXEIRA, Sandra Oliveira. O draconiano ajuste fiscal do Brasil e a expropriação de direitos da seguridade social. In: SALVADOR, Evilásio; BEHRING, Elaine; LIMA, Rita de Lourdes (orgs.). Crise do capital e fundo público: implicações para o trabalho, os direitos e a política social. São Paulo: Cortez, 2019.

CALIL, Gilberto. A realidade da pandemia no Brasil entre o discurso normalizador e a realidade preocupante. Disponível em: https://esquerdaonline.com.br/2020/09/21/arealidade-da-pandemia-no-brasil-entre-o-discurso-normalizador-e-a-realidadepreocupante/. Acesso em: 17 out. 2020.

CÂMARA DOS DEPUTADOS. Consultoria de Orçamento e Fiscalização Financeira. Assistência Social — PLOA 2020. Brasília, out. 2019.

CAVALLAZZI, Rosangela Lunardelli; SILVA, Sayonara Grillo Coutinho Leonardo da. Políticas de austeridade no Brasil contemporâneo: retrocessos laborais e consumeristas (218 de 017-2019). Revista de Direito do Consumidor (RDC), n. 126. Disponível em: https:// revistadedireitodoconsumidor.emnuvens.com.br/rdc/article/view/1280. Acesso em: 18 out. 2020.

CISLAGHI, Juliana Fiuza. Do neoliberalismo de cooptação ao ultraneoliberalismo: respostas do capital à crise. Partes I, II e III, 2020. Disponível em: https://esquerdaonline.com. br/2020/06/08/do-neoliberalismo-de-cooptacao-ao-ultraneoliberalismo-respostas-docapital-a-crise/. Acesso em: 18 out. 2020.

DEMIER, Felipe. Depois do golpe: a dialética da democracia blindada no Brasil. Rio de Janeiro: Mauad, 2017. 
IBGE. Estimativas da População. Disponível em: https:/www.ibge.gov.br/estatisticas/ sociais/populacao/9103-estimativas-de-populacao.html?edicao=28674\&t=resultados . Acesso em: 17 out. 2020

IBGE./ PNAD Contínua 2019. Disponível em: https://agenciadenoticias.ibge.gov.br/agenciasala-de-imprensa/2013-agencia-de-noticias/releases/27594-pnad-continua-2019rendimento-do-1-que-ganha-mais-equivale-a-33-7-vezes-o-da-metade-da-populacaoque-ganha-menos. Acesso em: 18 out. 2020.

MANDEL, Ernest. Capitalismo tardio. São Paulo: Abril Cultural, 1972/1982. (Os Economistas).

MANDEL, Ernest. Sobre o fascismo. Lisboa: Antídoto, 1976.

MANDEL, Ernest. A crise do capital: os fatos e sua interpretação marxista. São Paulo: Ensaio, 1990.

MARX, Karl. O capital. Livro 1 [1867]. São Paulo: Boitempo, 2013.

MATTOS, Marcelo Badaró. Governo Bolsonaro: neofascismo e autocracia burguesa no Brasil. São Paulo: Usina Editorial, 2020.

MÉSZÁROS, István. Para além do capital. São Paulo: Boitempo Editorial; Campinas: Editora da Unicamp, 2002.

SALVADOR, Evilasio. Fundo público e conflito distributivo em tempos de ajuste fiscal no Brasil. In: CASTRO, Jorge Abrahão de; POCHMANN, Márcio. Brasil: Estado social contra a barbárie. São Paulo: Fundação Perseu Abramo, 2020.

TROTSKY, León. Sobre o fascismo. Lisboa: Antídoto, 1931/1976.

\section{Sobre as autoras}

IVANETE BoschetTI - Assistente social e professora titular da Escola de Serviço Social (ESS).

E-mail: ivaboschetti@gmail.com

Elaine Rossetti Behring - Assistente social e professora da Faculdade de Serviço Social.

E-mail: elan.rosbeh@uol.com.br 